\title{
Depression among Women during Post-Partum Period: A Cross Sectional Study
}

\author{
Rajesh SS ${ }^{1}$, Venkatesh $\mathbf{P}^{2}$, Ashok $\mathbf{J}^{3}$, Krishna Iyengar ${ }^{3}$, Bobby Abraham ${ }^{4}$, Chaithra Devaraj ${ }^{4}$
}

${ }^{1}$ Assistant Professor, ${ }^{2}$ Associate Professor, ${ }^{3}$ Professor \& Head, ${ }^{4}$ Intern. Department of Community Medicine, Sri Siddhartha Medical College \& Research Centre, Tumakuru, Karnataka, India.

DOI -10.46319/RJMAHS.2018.v01i01.005

\begin{abstract}
Introduction: Depression is a common mental disorder characterised by sadness, loss of interest or pleasure, feelings of guilt or low self-worth, disturbed sleep or appetite, feelings of tiredness and poor concentration. Approximately $50-80 \%$ of women suffering from postpartum blues in the puerperal period, with about $20 \%$ of them developing postpartum depression. So, this study is carried out with the objective to assess the depression during post-partum period among women in Tumakuru by using Edinburgh Postnatal Depression Scale. Materials and Methods: This cross-sectional study was conducted in the outpatient department of Sri Siddhartha Medical College Hospital and District hospital, Tumakuru from November 2016 to May 2017. Total number of participants were 100. Data was collected using interview method by using Edinburgh Postnatal Depression Scale. Descriptive statistics was done to get frequencies and percentages and chi square test was applied. Results: Out of 100 women, $16(16 \%)$ belong to 19 to 21 years of age; the mean age being 23.6 years and standard deviation of 2.425 . In our study, $60(60 \%)$ women experienced depression during their postnatal period. $74.1 \%$ of women experienced depression among the age group 26 to 29 , there was no significant association between maternal age and depression among the study population. Conclusion: The above study shows that $60 \%$ of the woman suffer from postnatal depression. There is no significant association between the age, area of residence, mode of delivery, sex of the baby and depression among the study population
\end{abstract}

Key-words: Depression, postnatal period, post-partum period, Edinburg postnatal depression scale

\section{Introduction}

Depression is a common mental disorder characterised by sadness, loss of interest or pleasure, feeling of guilt or low self-worth, disturbed sleep or appetite, feeling of tiredness and poor concentration. ${ }^{[1]}$ Approximately $50-80 \%$ of women suffering from postpartum blues in the puerperal period, with about $20 \%$ of them developing postpartum depression ${ }^{[2]}$ However, there is a wide variation in prevalence of postpartum depression with $8-50 \%$ of postnatal mothers affected in different countries. $^{[3-7]}$ Postnatal depression, also known as postpartum depression is defined as depression with onset usually within 6 weeks of delivery ${ }^{[1]}$ Mothers face emotional difficulties, in some cases they may even be unaware that their distress has a name. ${ }^{[8]}$ Depression occurring in the postpartum periods may predispose to chronic or recurrent depression and cause adverse maternal and foetal outcomes and quality of care of the newborn. ${ }^{[1,3,4]}$

Postnatal depression seems to have multi factorial etiology encompassing demographic, economic, psychosocial, obstetric and medical risk factors. ${ }^{[9]}$ Postnatal depression is one of the most common psychopathology and is considered as a serious public health issue because of its devastating effects on mother, infant and family. ${ }^{[10]}$ The prevalence of Postnatal depression shows a wide range from $6 \%$ to $48 \%{ }^{[11]}$ The various predictors of postpartum depression are past history of psychopathology, psychological disturbance during pregnancy, poor marital relationship, low social

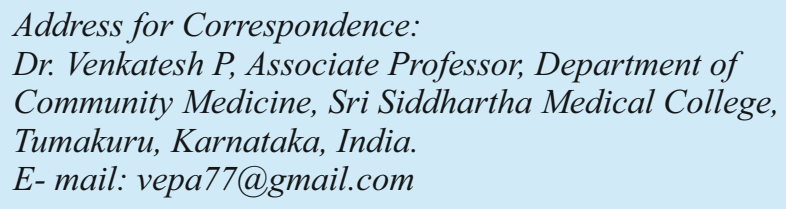


support and stressful life events. So, this study is carried out with the objectives to assess the depression among post-partum women in a tertiary care hospital by using Edinburgh Postnatal Depression Scale and to find out the association between Postnatal Depression and selected Demographic Variables of a postnatal mother.

\section{Materials and methods}

This cross-sectional study was conducted in the outpatient department of Sri Siddhartha Medical College Hospital and District hospital, Tumakuru between November 2016 to May 2017. Postnatal mothers attending outpatient department of Sri Siddhartha Medical College Hospital and District Hospital Tumakuru, were the study participants. Written informed consent was obtained from the study participants. Inclusion criteria being post-natal mothers within 6 weeks and exclusion criteria being past history of psychiatric illness. Data was collected using Edinburgh Postnatal Depression Scale. It is a 10 item self-report scale based on one-week recall, designed to screen Postnatal Depression in community. Each item is rated from 0 to 3 , yielding a total score of $0-30$, a cut-off score of $\geq 14$ was used to diagnose Postnatal Depression. The sample size was calculated using a study done by Johnson AR et.al by using the formula $4 \mathrm{pq} / \mathrm{d}^{2}$ where $\mathrm{p}$ is prevalence of $45.5 \%, \mathrm{q}=100-\mathrm{p}$ and $\mathrm{d}$ is allowable error of $10 \%$, which was found to be minimum of 95 subjects. A total 100 subjects were included in the study. ${ }^{[12]}$

Data were compiled in an Excel spreadsheet. The data were analyzed using SPSS software, version 16.0. Descriptive statistics was done to get frequencies and percentages, and chi square test was applied to observe the association between postnatal depression and variables such as age, address, mode of delivery and sex of the baby. A $P$-value less than 0.05 was considered statistically significant.

\section{Results}

In our study, 100 women were enrolled of age 19 to 29 years from rural and urban areas who delivered male and female babies through normal and caesarean section deliveries in Sri Siddhartha Medical College and Research centre and District Hospital Tumakuru.

Out of 100 women $16(16 \%)$ belong to 19 to 21 years of age, 57 (57\%) belong to 22 to 25 years of age and 27 ( $27 \%$ ) belong to 26 to 29 years of age; the mean age
Table 1: Sociodemographic and delivery outcome characteristics of the study population.

\begin{tabular}{ccc}
\hline $\begin{array}{c}\text { Sociodemographic } \\
\text { profile }\end{array}$ & Frequency & Percentage \\
\hline Age in years & & \\
$<=21$ & 16 & 16 \\
$22-25$ & 57 & 57 \\
$26-29$ & 27 & 27 \\
Place of Residence & & \\
Rural & 76 & 76 \\
Urban & 24 & 24 \\
Mode of delivery & & \\
Normal & 40 & 40 \\
Section & 60 & 60 \\
Sex of the baby & & \\
Female & 68 & 68 \\
Male & 32 & 32 \\
Total & $\mathbf{1 0 0}$ & $\mathbf{1 0 0}$ \\
\hline
\end{tabular}

being 23.6 years and standard deviation of 2.425 and 76 (76\%) belong to rural area and 24 (24\%) belong to urban area and $40(40 \%)$ delivered normally and $60(60 \%)$ delivered through caesarean section. 68 (68\%) delivered female babies and $32(32 \%)$ delivered male babies (Table 1). In our study, $60(60 \%)$ women experienced depression during their postnatal period (Table 2).

Table 2: Proportion of Postnatal Depression among study population

\begin{tabular}{ccc}
\hline $\begin{array}{c}\text { Postnatal } \\
\text { Depression }\end{array}$ & Frequency & Percent \\
\hline No & 40 & 40 \\
Yes & 60 & 60 \\
Total & $\mathbf{1 0 0}$ & $\mathbf{1 0 0}$ \\
\hline
\end{tabular}

$74.1 \%$ of women experienced depression among the age group of 26 to 29 years, there was no significant association between maternal age and depression among the study population. $64.5 \%$ of rural women experienced depression in their postnatal period, there was no significant association between the area of residence and depression among the study population. $65 \%$ of women who underwent caesarean section experienced depression, there was no significant association between the mode of delivery and depression among the study population. $64.7 \%$ women 
Table 3: Association between the Sociodemographic characteristics and Postnatal Depression

\begin{tabular}{ccccc}
\hline \multirow{2}{*}{ Parameters } & \multicolumn{2}{c}{ Postnatal Depression } & \multirow{2}{*}{ Total (\%) } & \multirow{2}{*}{ P value } \\
\hline Agse in years & & & & 0.104 \\
$<=21$ & $6(37.5)$ & $10(62.5)$ & $16(100.0)$ & \\
$22-25$ & $27(47.4)$ & $30(52.6)$ & $57(100.0)$ & \\
$26-29$ & $7(25.9)$ & $20(74.1)$ & $27(100.0)$ & \\
Place of Residence & & & & 0.104 \\
$\quad$ Rural & $27(35.5)$ & $49(64.5)$ & $76(100.0)$ & \\
$\quad$ Urban & $13(54.2)$ & $11(45.8)$ & $24(100.0)$ & \\
Mode of delivery & & & & 0.211 \\
$\quad$ Normal & $19(47.5)$ & $21(52.5)$ & $40(100.0)$ & \\
$\quad \begin{array}{c}\text { Caesarean } \\
\text { Sex of the baby }\end{array}$ & $21(35.0)$ & $39(65.0)$ & $60(100.0)$ & \\
$\quad$ Female & $24(35.3)$ & $44(64.7)$ & $68(100.0)$ & \\
$\quad$ Male & $16(50.0)$ & $16(50.0)$ & $32(100.0)$ & \\
\hline
\end{tabular}

who delivered female babies experienced depression in their postnatal period, there was no significant association between the sex of the baby and depression among our study population (Table 3 ).

\section{Discussion}

Proportion of depression among postnatal mothers according to this study is $60 \%$ which is higher than the other studies, like a study done by Kruthika.K. et al in Belagavi, Karnataka, the prevalence of postnatal depression was $13.6 \%$ and in Mandya district Prevalence of postnatal depression was $31.4 \%$ and $45 \%$ was the prevalence in a study done in Ramanagar rural area. ${ }^{[12,13]} \mathrm{A}$ study done in rural area of Wardha district showed $24 \%$ mothers were chronically depressed after childbirth. In one more study done by Ashish $\mathrm{V}$ et al in Bhavnagar showed the prevalence of depression was $11 \%{ }^{[1,14]}$ In one more study done in Kolkata - $25 \%$ was the prevalence, but in a study done by Muna Silwal et al in Mangalore to assess the level of anxiety and depression among postnatal mothers concluded that 3 percentage of the subject had severe depression, 19 percentage had moderate depression and 78 percentage had mild level of depression. ${ }^{[12,13]}$ The overall prevalence of Postpartum depression (PPD) was $17.1 \%$ in Nepal with a mean age of 24.34 years. ${ }^{[11]}$ Similar to the present study no significant association was found between postnatal depression and age, education, occupation, religion, type of family, family history of psychiatric illness, complications during pregnancy and childbirth in a study conducted in rural Karnataka. Unlike the present study, birth of female child, nuclear family structure and poor marital relationship were found to have a statistically significant correlation with peripartum depression in a study conducted in Delhi which showed a significant association between female baby and Postnatal depression. ${ }^{[15]}$

\section{Conclusion}

The above study shows that out of 100 women, $60 \%$ suffer from postnatal depression. There was no significant association between the age, area of residence, mode of delivery, sex of the baby and depression among the study population.

\section{Financial support and sponsorship: Nil}

\section{Conflicts of interest: Nil}

\section{References}

1. Nikhil.D, Meenakshi K, Smruthiranjan N, Abhay M. Assessment of Postnatal Depression among Mothers following Delivery in Rural India of Wardha District; Innovative Journal of Medical and Health Science 4:2 March-April 2014:53-55

2. Miller LJ. Pospartum depression. JAMA. 2002; 287 : 762-6.

3. Perfetti J, Clark R, Fillmore CM. Postpartum depression: identification, screening, and treatment. WMJ. 2004; 103(6): 56-63. 
4. Teissedre F, Chabrol H. A study of the Edinburgh Postnatal Depression Scale (EPDS) on 859 mothers: detection of mothers at risk for postpartum depression. Encephale 2004;30(4):376-81.

5. Suda S, Segi-Nishida E, Newton SS, Duman RS. A postpartum model in rat: behavioral and gene expression changes induced by ovarian steroid deprivation. Biol Psychiatry. 2008;64(4):311-9.

6. Del Rosario G, Chang C, Lee E. Postpartum depression: symptoms, diagnosis, and treatment approaches. J Am Acad Phys Assist. 2013;26(2):50-4.

7. Parsons CE, Young KS, Rochat TJ, Kringelbach ML, Stein A. Postnatal depression and its effects on child development: a review of evidence from low- and middleincome countries. Br Med Bull. 2012; 101: 57-79. doi: $10.1093 / \mathrm{bmb} /$ indro047.

8. Hearn G, Iliff A, Jones I, Kirby A, Ormiston P, Parr P, et al. Postnatal depression in the community. Br J Gen Pract. 1998; 48:1064-1066.

9. O'Hara MW, Swain AM. Rates and risk of postpartum depression-a meta-analysis. Int Rev Psychiatry1996; $8: 37-54$.

10. Shivalli S, Gururaj N. Postnatal Depression among Rural Women in South India: Do Socio-Demographic, Obstetric and Pregnancy Outcome Have a Role to Play? PLoS ONE 10(4):e0122079. doi:10.1371/journal.pone.0122079

11. Bhusal B R, Bhandari N, Chapagai M and Gavidia T, Depression Scale as a screening tool for postpartum depression in Kathmandu, Nepal Int J Ment Health Syst (2016) 10:71 .DOI 10.1186/s13033-016-0102-6

12. Johnson AR, Edwin S, Joachim N, Mathew G, Ajay S, Joseph B. Postnatal depression among women availing maternal health services in a rural hospital in South India. Pak J Med Sci 2015;31(2):408-413. doi: http://dx.doi.org/10.12669/pjms.312.6702

13. Kruthika.K, Sharavanan E U, M.D.Mallapur. Epidemological study of postnatal depression among women availing maternal health services in rural areas of Belagavi Karanataka, India. International journal of Community Medicine and Public Health 2017 Mar4(3); 759-763.

14. Ashish V,Amit V;Sreening for Postpartum Depression; Gujarat Medical Journal;Dec2013 Vol 68No 2 Dubey C

15. Gupta N, Bhasin S, Muthal RA, Arora RInt J Soc Psychiatry. Prevalence and associated risk factors for postpartum depression in women attending a tertiary hospital, Delhi, India. Int J Soc Psychiatry. 2012 Nov;58(6):577-80. doi: 10.1177/0020764011415210. Epub 2011 Aug 5. 